\title{
ANALISIS FRAMING MEDIA: STUDI KOMPARATIF MEDIA ONLINE "CNN" DAN "KOMPAS" TERKAIT FENOMENA KEMANUSIAAN DI AL-AQSA PERIODE 20 - 23 JULI 2017
}

\author{
Netty Siswanti \\ London School of Public Relations Jakarta \\ Email: siswantinetty@yahoo.com
}

\begin{abstract}
Abstrak
Artikel ini fokus pada analisis perbedaan framing berita yang dilakukan oleh media massa nasional Indonesia dan media massa internasional yakni media online cnnindonesia.com dan kompas.com. Pemberitaan yang diambil terkait fenomena kemanusiaan di Al-Aqsa. Peneliti berusaha melihat bagaimana kedua media tersebut memainkan perannya sebagai media massa di dalam dinamika politik dunia. Dasar teori yang digunakan adalah ekonomi politik internasional dan analisis framing. Penelitian ini menggunakan metode penelitian kualitatif dengan analisis framing yang telah mengumpulkan data dari berita-berita pada periode 20 - 23 Juli 2017 dari cnnindonesia.com dan kompas.com. Hasil penelitian ini menunjukkan bahwa dua media online cnnindonesia.com dan kompas.com memiliki pandangan yang berbeda mengenai fenomena kemanusiaan di Al-Aqsa dan memrepresentasikan bahwa setiap media massa memiliki keberpihakan tertentu dengan Negara asal media tersebut. Pemberitan ini banyak dipengaruhi oleh ekonomi politik internasional dan kepentingan media massa tersebut.
\end{abstract}

Kata Kunci: Analisis Framing, Media Massa, Media Online, Al-Aqsa

\begin{abstract}
This study analyzes news about the phenomenom of humanity in Al-Aqsa which can not separate mass media spotlight national and international focusing on point of view from online media cnnindonesia.com and kompas.com for seeing how different news framing by both media. The basic theory used is the theory of mass media, media and politic economy international and framing. This study uses qualitative methods and framing analysis by collected data from news period 20 - 23 July 2017 from cnnindonesia.com and kompas.com. This study shows both online media cnnindonesia.com and kompas.com have a different point of view about the phenomenom of humanity in Al-Aqsa and this shows that mass media has certain partiality with origin country. This al-Aqsa news is much influence by international political economy and the interest of mass media.
\end{abstract}

Keywords: Framing Analysis, Mass Media, Online media, Al-Aqsa

\section{PENDAHULUAN}

Media massa adalah salah satu wadah bagi masyarakat untuk mengetahui dan mendapatkan informasi dengan cepat dan mudah. Informasi adalah kebutuhan bagi setiap manusia di dunia ini karena dengan adanya informasi setiap manusia dapat mengetahui fenomena-fenomena serta kejadian apa saja dan di mana saja di seluruh dunia. Media massa 
adalah sarana yang membawa pesan, media massa utama adalah buku, majalah, koran, televisi, radio, rekaman, film dan web. Kebanyakan ahli teori menganggap media sebagai wahana yang netral dalam memuat pesan (Vivian, 2008, p. 453). Dimana media massa nasional dan internasional banyak memberitakan tentang apa yang terjadi di Masjid Al-Aqsa yang disinyalir adanya pelanggaran hak asasi manusia karena selain larangan ibadah atau pembatasan beribadah oleh Israel, ketegangan antara Israel dan Palestina semakin memanas. Konflik kedua negara tersebut yang sudah berlangsung bertahun - tahun lamanya serta telah memakan korban jiwa dan juga diperkuat dengan pernyataan oleh Tina Ustad Figenschou dalam bukunya Al Jazeera and The Global Media Landscape The South Is Taking Back yang dimana banyak membahas tentang media - media global dan isu - isu internasional.

"The war in Gaza, lasting from 27 December 2008 to 18 January 2009, was an asymmetric war with high numbers of civilian victims. During the three weeks of war, over 1,400 people (Amnesty International 2009) were killed, almost all of them Palestinians." (Figenschou, 2014, p. 118)

Tina mengatakan dengan jelas bahwa perang di Gaza yang berlangsung lama telah banyak memakan korban jiwa, serta dalam tiga minggu perang sudah lebih dari 1.400 orang menjadi korban.

Al- Aqsa memang bukanlah kasus baru bagi Indonesia serta dunia internasional, karena kasus Al-Aqsa tidak hanya menyangkut kasus agama, perebutan wilayah serta antara negara Palestina dan Israel bahkan kasus Al-Aqsa menyangkut adanya pelanggaran hak asasi manusia menjadi salah satu isu penting di PBB. Pola pikir serta persepsi masyarakat Indonesia terhadap kasus Al-Aqsa dengan mayoritas masyarakat Indonesia beragama Islam serta bergabungnya Indonesia dalam Organinasasi Kerjasama Islam (OKI) sehingga media Indonesia secara tidak langsung terlihat membela Palestina dan berpihak kepada perjuangan Palestina untuk mendapatkan haknya (Eriyanto, 2002, p. 6).

Ada dua media online besar yang dipilih oleh peneliti sebagai acuan media online di Indonesia yang cukup massive memberitakan kasus Al-Aqsa. Media online tersebut adalah cnnindonesia.com dan kompas.com, cnnindonesia.com yang merupakan gabungan kekuatan media global Turner Broadcasting System atau Cable News Network (CNN) dengan perspektif lokal media nasional yaitu Transmedia yang baru diluncurkan tahun 2014 (liputan6, 2014) sedangkan kompas.com adalah sebagai salah satu pionir media online di Indonesia ketika pertama kali hadir di Internet pada 14 September 1995 dengan nama Kompas Online (Kompas, n.d). Kedua media online besar ini yang dipilih peneliti untuk menggambarkan kasus yang ingin diteliti karena peneliti merasa CNN Indonesia yang berlatar belakang perusahaan media besar amerika yang menjadi situs berita paling popular dimuka bumi berkerja sama dengan Trans Media yaitu perusahaan media lokal Indonesia yang baru terjalin 2014 lalu memiliki pandangan sendiri terkait setiap fenomena yang ada didunia karena memiliki keterikatan dengan dua perusahaan media besar nasional dan internasional sedangkan kompas.com yang berlatar belakang perusaan media cetak yang murni milik nasional yang berjuang dari awal masa Indonesia (Inside.kompas, n.d). 
Salah satunya pada 23 Juli 2017 di nasional.kompas.com yang menuliskan pernyataan Wakil Ketua Komisi 1 DPR RI Meutya Hafid yang mengatakan dengan jelas bahwa dia mengecam keras penembakan yang dilakukan oleh pihak keamanan Israel terhadap tiga jemaah Palestina dan Meutya juga menegaskan bahwa dirinya mendukung Indonesia untuk segera mengajukan Pertemuan Darurat Dewan Keamanan Perserikatan Bangsa - Bangsa (PBB) serta Kompas.com dalam tulisannya di Kompas.com dibingkai dengan judul "Penembakan DI Al-Aqsa Dinilai Langgar HAM,PBB Diminta Bertindak" (Kompas, 2017). Sedangkan di hari yang sama cnnindonesia.com juga mengeluarkan berita mengenai Al-Aqsa yang menuliskan bahwa perseteruan Israel dan Palestina semakin memburuk dan ada tiga negara lain selain Indonesia yang juga mendesak Dewan Keamanan PBB segera bersidang karena situasi di Yerusalem memanas setelah adanya pemasangan detektor logam di area Masjid Al-Aqsa serta adanya penikaman terhadap dua polisi Israel yang bertugas di area tersebut dalam tulisan beritanya CNN membingaki beritanya dengan judul "PBB Didesak Segera Bersidang Atasi Kemelut di Yerusalem" (CNN Indonesia, 2017).

Penulis memilih untuk melakukan studi komparatif pada media cnnindonesia.com dan Kompas.com dalam membentuk suatu framing yang terkait fenemona kemanusiaan di Al-Aqsa, karena kedua media tersebut menjadi salah satu sumber masyarakat untuk mendapatkan informasi secara online di Indonesia. Penulis merasa penting untuk mengkaji dan meneliti karena adanya perbedaan dalam penulisan judul serta isi dari berita tersebut mendorong penulis untuk meneliti lebih jauh peran media online CNN melalui cnnindonesia.com dan kompas melalui kompas.com dalam terkait fenomena kemanusiaan di Al-Aqsa.

Media mempengaruhi hampir seluruh aspek kehidupan masyarakat, media tidak hanya menyediakan hiburan melainkan informasi - informasi penting untuk masyakarakat (Biagi, 2010, p. 5). Media yang berbeda - beda mewakili pesan yang berbeda - beda, media adalah salah satu komponen yang bisa menciptakan dan mempengaruhi hubungan hubungan serta kegiatan manusia antar individu atau masyarakat (Tamburuka, 2013, p. 71). Dennis Mc. Quail mengatakan bahwa media massa adalah bisa dikatakan komunikasi massa yang meskipun sebagain besar menggunakan media sebagai alat. Beberapa komponen penting media massa menurut Dennis Mc. Quail adalah adanya tujuan komunikasi tertentu sesuai dengan tujuan, kebutuhan serta kegunaannya serta mengunakan teknologi untuk berkomunikasi kepada masyarakat dari kejauhan, media massa juga membentuk norma organisasi sosial untuk membentuk keterampilan dan kerangka kerja untuk produksi dan distribusinya serta membentuk norma regulasi dan kontrol (McQuail, 2010, p. 24).

Disini dapat kita simpulkan adalah bahwa media massa menjadi wadah untuk berkomunikasi kepada masyarakat menggunakan media atau alat komunikasi lainnya. Seperti yang kita ketahui alat media massa ada bermacam - macam dengan kemajuan zaman sekarang media massa tidak hanya media cetak seperti buku, majalah, surat kabar, serta tidak hanya rekamanan atau radio tetapi juga film dan sangat mengikuti zaman serta kebutuhan manusia. Karena teknologi komunikasi memainkan peran penting dalam tatanan sosial dan 
budaya baru yang membawa perubahan dari media cetak ke media elektronik (Tamburuka, 2013, p. 71).

\section{Media dan Ekonomi Politik Internasional}

Ekonomi dan politik merupakan dua hal yang yang tidak bisa dipisahkan juga dengan media pada zaman modern sekarang, ekonomi dan politik saling berkaitan di dunia media entah itu di media nasional maupun media internasional. Menurut Marxist Hal fundamental bagi pemahaman struktur media adalah persoalan kepemilikan yang dijalankan, kepercayaan bahwa kepemilikan sangat menentukan sifat media serta mendorong hubungan langsung antara kepemilikan ekonomi dan penyebaran pesan yang meneguhkan legitimasi dan nilai dari masyarakat kelas. Teori media Marxist di abad ke - 20 lebih berkosentrasi pada ide daripada struktur materi yang menekankan pada ideologi efek dari media terhadap kepentingan kelas pengusaha dalam "memproduksi" hubungan yang intinya menipulatif (McQuail, 2011, pp. 105-254). Inilah membuat media massa memang memiliki peran besar di dalam kehidupan ekonomi serta politik.

Kunci dari media adalah bahwa setiap aktivitasnya yang tidak terpisahkan secara ekonomi maupun politik (McQuail, 2011, p. 244). Tidak dipungkiri media massa mempengaruhi budaya, kebiasaan membeli serta politik kita. Tiga konsep penting tentang media massa yang perlu diingat (Biagi, 2010, p. 13), yaitu:

1. Media massa merupakan usaha yang berpusat pada keuntungan

2. Media massa mengubah cara pengiriman serta komsumsi media massa itu sendiri

3. Media massa mencerminkan sekaligus mempengaruhi politik, masyarakat dan budaya

Pernyataan diatas menjelaskan bahwa memang media massa mempengaruhi kehidupan kita baik secara ekonomi maupun politik. Media massa ketika dipakai untuk menggambarkan usaha atau bisnis media dia memiliki tujuan utama yaitu untuk menghasilkan uang ini yang membuat bahwa media massa selalu berkaitan dengan sistem ekonomi kita. Karena media massa adalah bisnis yang berpusat pada keutungan maka media massa memiliki produk yaitu hiburan serta informasi yang bergantung pada ketertarikan masyarakat karena untuk memenuhi kebutuhan masyarakat akan informasi, memengaruhi pemerintah suatu Negara, menyebarkan budaya, menawarkan hiburan dan menyediakan sarana untuk mengekpresikan diri (Biagi, 2010, p. 14).

\section{Analisis Framing}

Framing adalah salah satu pendekatan untuk mengetahui bagaimana perspektif atau cara pandang yang digunakan oleh wartawan ketika menyeleksi isu dan menulis berita yang pada akhirnya menentukan fakta apa yang diambil, bagian mana yang ditonjolkan atau dihilangkan dan hendak dibawa kemana berita tersebut (Eriyanto, 2002, p. 261). Gagasan mengenai Framing, pertama kali dilontarkan oleh Beterson tahun 1955 mulanya frame dimaknai sebagai struktur konseptual atau perangkat kepercayaan yang mengorganisir pandangan politik, kebijakan, dan wacana serta realitas (Baran \& Davis, 2010,pp. 390-394). Menurut peneliti ini berkaitan dengan apa yang akan peneliti bahas yaitu fenomena 
kemanusiaan di Al-Aqsa pada periode 20 - 23 juli 2017 yang terus diberitakan oleh kedua media yang dipilih peneliti. Proses framing selalu menyertakan pengolahan informasi yang kompleks menjadi suatu informasi yang sederhana dan memakai label serta bingkai yang mudah dikenal. Frame menunjuk skema pemahaman individu sehingga seseorang dapat menempatkan, mempersepsi, mengidentifikasi, dan memberikan label peristiwa dalam pemahaman tertentu inilah yang mendasari peneliti untuk melihat dengan jelas yang berfokus pada fenomena kemanusiaan di Al-Aqsa (Eriyanto, 2002, p. 218).

Untuk mengetahui bagaimana pembingkaian yang dilakukan oleh dua media online yaitu cnnindonesia.com dan Kompas.com terdapat sebuah perangkat framing yang dikemukakan oleh William A.Gamson dan Andre Modigliani yaitu bagaimana seseorang atau media memahami dan memaknai suatu isu dan fenomena ada dua perangkat bagaimana ide sentral yang menurut gamson framing itu sendiri dipahami sebagai seperangkat gagasan atau ide sentral ketika seseorang atau media memahami dan memaknai isu serta ide sentral yang akan didukung perangkat wacana lain sehingga antara bagian satu wacana dan lainnya saling mendukung yang terbagi menjadi dua perangkat framing (Eriyanto, 2002, pp. 262263), yaitu:

\section{Framing Device (Perangkat Framing)}

Perangkat ini berhubungan langsung dengan bingkai yang ditekankan pada teks berita, yang ditandai dengan pemakaian kata, kalimat, gambar, grafik serta perumpamaan atau pengandaian.

2. Reasoning Devices (Perangkat Penalaran)

Perangkat ini berhubungan dengan dasar pembenar atau padangan yang membuat suatu gagasan terlihat benar, bias dan demikian adanya. Karena untuk mempermudah masyarakat menerima pesan harus ada gagasan yang tampat benar, bias agar tidak ada yang mempertanyakan suatu gagasan atau pesan tersebut.

\section{METODOLOGI PENELITIAN}

Penelitian ini menggunakan penelitian kualitatif dengan analisis framing untuk mengkomparasikan pemberitaan dari dua media yang berbeda. Komparasi atau perbandingan menurut Todd Landman dalam buku Metode Penelitian Hubungan Internasional adalah merupakan aktivitas manusia yang alami, sejak purbakala hingga sekarang, generasi manusia telah berusaha untuk memahami dan menjelaskan persamaan dan perbedaan yang mereka lihat antara diri mereka dan orang lain atau dengan kata lain membandingkan. Metode komparatif atau comparative method telah lama digunakan dalam studi lintas budaya untuk mengidentifikasi, menganalisis, dan menjelaskan perbedaan persamaan lintas budaya (Bakry, 2016, p. 230). Munurut Linda Hantrais metode komparatif adalah metode yang digunakan untuk studi lintas nasional dan komparatif, yakni ketika bermaksud untuk meneliti isu-isu atau fenomena tertentu antara dua Negara untuk membandingkan manifestasi mereka dalam berbagai setting sosial budaya, dengan menggunakan instrument penelitian yang sama baik untuk melakukan analisis sekunder data nasional atau untuk melakukan penelitian empiris yang baru yaitu bertujuan untuk mencari penjelasan atas persamaan dan perbedaan, untuk membuat generalisasi dari persamaan dan 
perbedaan tersebut atau untuk mendapatkan kesadaran yang lebih besar dan pemahaman yang lebih dalam mengenai realitas sosial dalam konteks nasional yang berbeda (Bakry, 2016, p. 231). Dalam hal ini metode komparatif digunakan untuk mengetahui perbedaan framing antar media global yang bekerjasama dengan media nasional yaitu cnnindonesia.com dan kompas.com yang murni media nasional.

Dalam penelitian ini dilakukan analisis framing yaitu suatu metode yang ditunjukan untuk mencari tema - tema kunci didalam teks, serta menunjukan bagaimana tema - tema budaya membentuk pemahaman terhadap suatu peristiwa. Analisis framing dipakai untuk melihat bagaimana media mengkontruksikan realitas serta pembentukan pesan atau makna dari teks yang disajikan kepada khalayak (Pambayun, 2013, p. 375). Analisis framing yang digunakan peneliti dalam penelitian ini adalah teknik analisis framing menurut William A. Gamson. Ini didasari karena analisis framing Gamson fokus pada gerakan - gerakan sosial serta menurut peneliiti sangan cocok untuk menganalisis terkait fenomena kemanusiaan di Al-Aqsa yang bisa jadi memunculkan gerakan - gerakan sosial. Disini Gamson menggunakan perangkat framing yang ia kemukakan dengan Andre Modigliani yaitu setiap analisis framing yang menyebutkan ada dua perangkat yaitu framing devices (perangkat framing) dan reasoning devices (perangkat penalaran) untuk melihat dengan jelas framing kedua media yaitu cnnindonesia.com serta kompas.com terkait fenomena kemanusiaan di Al-Aqsa periode 20-23 Juli 2017.

Tabel 1. Perangkat Framing William A Gamson dan Andre Modigliani

\section{Frame}

Central organizing idea for making sense of relevant event, suggesting what is at issues

Framing Devices Reasoning Devices

(Perangkat framing)

(Perangkat penalaran)

\section{Metaphors}

Perumpamaan atau pengandaian

Catchphrases

Frase yang menarik, kontras, menonjol dalam suatu wacana. Ini umumnya berupa jargon atau slogan.

\section{Exemplaar}

Mengaitkan bingkai dengan contoh, uraian (bisa berupa teori, perbandingan) yang memperjelas bingkai

\section{Depiction}

Penggambaran atau pelukisan suatu isu yang bersifat konotatif. Depiction ini umumnya berupa kosakata, leksikon untuk melabeli sesuatu.

\section{Visual Image}

Gambar, grafik, citra yang mendukung

\section{Roots}

Analisis kausal atau sebab akibat Appeals to Principle

Premis dasar, klaim klaim moral

\section{Consequences}

Efek atau konsekuensi yang didapat dari bingkai 
bingkai secara keseluruhan. Bisa berupa

foto, kartun, ataupun grafik untuk

menekankan dan mendukung pesan

yang ingin disampaikan.

Sumber: Eriyanto, 2002, pp. 262-263.

\section{HASIL DAN PEMBAHASAN}

Fokus penelitian dari penelitian ini adalah untuk melihat bagaimana kedua media online yaitu cnnindonesia.com dan kompas.com periode 2017 menampilkan framing berita mereka dalam membangun persepsi terkait fenomena kemanusiaan di Al-Aqsa periode 20 23 Juli 2017. Berikut daftar berita yang menjadi fokus penelitian ini:

Tabel 2. Pemberitaan Konflik Al-Aqsa periode 20 - 23 Juli 2017 oleh cnnindonesia.com dan kompas.com

\begin{tabular}{|c|c|c|c|}
\hline No & Tanggal & Cnnindonesia.com & Kompas.com \\
\hline 1 & $20-7-2017$ & $\begin{array}{l}\text { Gedung Putih 'Prihatin' } \\
\text { Atas Kisruh Al-Aqsa }\end{array}$ & $\begin{array}{ll}\text { Pemerintah } & \text { Indonesia } \\
\text { Kecam } & \text { penutupan } \\
\text { Kompleks Majid Al-Aqsa }\end{array}$ \\
\hline 2 & $23-7-2017$ & $\begin{array}{l}\text { PBB Didesak Segera } \\
\text { Bersidang Atasi Kemelut } \\
\text { di Yerusalem }\end{array}$ & $\begin{array}{l}\text { Penembakan di Al-Aqsa } \\
\text { Dinilai Langgar HAM, } \\
\text { PBB Diminta Bertindak }\end{array}$ \\
\hline
\end{tabular}

Sumber: Data Olahan Peneliti, 2017.

Berdasarkan hasil penelitian yang telah dilakukan terhadap sepuluh artikel dari media online cnnindonesia.com dan kompas.com mengenai pandangan kedua media terhadap fenomena kemanusiaan di Al-Aqsa periode 20 - 23 Juli 2017, peneliti menemukan perbedaan antara sudut pandang yang cenderung keberpihakan salah satu media terhadap Negara Indonesia dan Palestina dan salah satu media terlihat netral akan tetapi dalam penulisannya lebih pro Amerika dan tidak terlalu menyalahkan Israel dalam kejadian itu berkaitan dengan ekonomi politik internasional yang dilihat dengan menggunakan metode analisis framing William A gamson dan Andre Modigliani.

Tabel 3. Perbedaan Framing pada Berita 1 Edisi 20 Juli 2017 Cnnindonesia.com dan Kompas.com

\begin{tabular}{|c|c|c|}
\hline Media Online & Cnnindonesia.com & Kompas.com \\
\hline Frame & Gedung Putih Prihatin & $\begin{array}{l}\text { Pemerintah } \\
\text { Mengecam }\end{array}$ \\
\hline Metaphors & $\begin{array}{l}\text { Menggantikan } \\
\text { seharusnya Amerika } \\
\text { Serikat menjadi simbol } \\
\text { yang kuat disini bahwa } \\
\text { tanpa menyebutkan } \\
\text { Amerika Serikat tapi } \\
\text { dengan menyebutkan } \\
\text { Gedung Putih }\end{array}$ & $\begin{array}{l}\text { Kata Pemerintah Indonesia yang } \\
\text { menurut peneliti menjadi simbol } \\
\text { inti dari maksud yang ingin } \\
\text { disampaikan diberita ini adalah } \\
\text { wawancara dengan dari Juru } \\
\text { bicara kemenlu Arrmanatha } \\
\text { Nasir }\end{array}$ \\
\hline Catchphrases & Amerika Serikat prihatin & Indonesia mengecam seolah ini \\
\hline
\end{tabular}




\begin{tabular}{|c|c|c|}
\hline & $\begin{array}{l}\text { terlihat dari judul yang } \\
\text { cnnindonesia.com but } \\
\text { yaitu membuat slogan } \\
\text { 'prihatin' } \\
\text { mempertegas yang } \\
\text { Amerika Serikat juga } \\
\text { peduli dengan kejadian di } \\
\text { Al-Aqsa dan ditambah } \\
\text { dengan pernyataan } \\
\text { didalam berita yaitu yang } \\
\text { ditulis sangat prihatin }\end{array}$ & $\begin{array}{l}\text { menggambarkan dengan jelas } \\
\text { bahwa Indonesia peduli terhadap } \\
\text { apa yang terjadi dan Indonesia } \\
\text { melakukan tindakan yang } \\
\text { signifikan yaitu melakukan } \\
\text { pembicaraan telepon dengan } \\
\text { Menlu Jordania }\end{array}$ \\
\hline Exemplaar & $\begin{array}{lr}\text { Mengatakan } & \text { bahwa } \\
\text { Amerika meminta Israel } \\
\text { dan kerajaan Yordania } \\
\text { untuk meredam } \\
\text { ketegangan dan mencari } \\
\text { solusi demi menjamin } \\
\text { keamanan dan } \\
\text { mempertahankan status } \\
\text { quo walaupun tidak secara } \\
\text { politik ikut campur dalam } \\
\text { kisruh }\end{array}$ & $\begin{array}{l}\text { Mengatakan bahwa Pemerintah } \\
\text { Indonesia kecam penutupan } \\
\text { kompleks Al-Aqsa dengan } \\
\text { mengutip wawancara dari Juru } \\
\text { bicara kemenlu Arrmanatha } \\
\text { Nasir }\end{array}$ \\
\hline Depiction & $\begin{array}{l}\text { Amerika Serikat peduli } \\
\text { walaupun tidak langsung } \\
\text { ikut campur hanya dengan } \\
\text { memberikan pernyataan } \\
\text { bahwa mereka sangat } \\
\text { prihatin dengan keadaan di } \\
\text { Al-Aqsa dan Israel yang } \\
\text { memulai kisruhpun } \\
\text { memiliki alasan mengapa } \\
\text { dia meningkatkan } \\
\text { keamanan di kompleks Al- } \\
\text { Aqsa dan kisruh yang } \\
\text { terjadi di Bukit Bait Suci } \\
\text { memicu pemasangan } \\
\text { detektor logam serta } \\
\text { protes yang dilakukan } \\
\text { warga muslim Palestina } \\
\text { dengan melakukan ibadah } \\
\text { diluar gerbang dan } \\
\text { penutupan akses ke Bait } \\
\text { Suci bagi umat Yahudi } \\
\text { dan pengunjung lainnya }\end{array}$ & $\begin{array}{l}\text { Pemerintah Indonesia mengecam } \\
\text { penutupan kompleks Masjid Al- } \\
\text { Aqsa dan melakukan upaya } \\
\text { dengan melakukan pembicaraan } \\
\text { dengan Menlu Jordania } \\
\text { membahas situasi di Masjid Al- } \\
\text { Aqsa }\end{array}$ \\
\hline Visual Images & $\begin{array}{l}\text { Gambar bahwa orang - } \\
\text { orang yang sedang sujud } \\
\text { atau melaksanakan sholat } \\
\text { diluar pagar akan tetapi } \\
\text { disekitarnya dijaga ketat }\end{array}$ & $\begin{array}{l}\text { Gambar juru bicara Kementrian } \\
\text { luar Negeri Arrmanatha Nasir } \\
\text { ketika Di Kemenlu, Jakarta }\end{array}$ \\
\hline
\end{tabular}




\begin{tabular}{|c|c|c|}
\hline & oleh pasukan bersenjata & \\
\hline Roots & $\begin{array}{l}\text { Israel memang melakukan } \\
\text { peningkatan keamanan } \\
\text { tapi dengan alasan } \\
\text { sedangkan Palestina } \\
\text { melakukan penyerangan } \\
\text { juga terhadap dua polisi } \\
\text { Israel dibagian timur. } \\
\text { Ketegangan di Bukit Bait } \\
\text { Suci bermula usai Israel } \\
\text { meningkatkan penjagaan } \\
\text { di situs suci dengan } \\
\text { memasang detektor logam } \\
\text { setelah dua tentara Israel } \\
\text { terbunuh pada Jumat, } \\
\text { disini menuliskan bahwa } \\
\text { dasar dari kisruh di A- } \\
\text { Aqsa adalah karena } \\
\text { pemasangan detektor } \\
\text { logam }\end{array}$ & $\begin{array}{l}\text { Penembakan yang menewaskan } \\
\text { dua polisi yang berakibat } \\
\text { ditutupnya kompleks masjid Al- } \\
\text { Aqsa serta terciptanya kericuhan } \\
\text { antara warga Palestina dan Israel } \\
\text { yang membuat pemerintah } \\
\text { Indonesia ikut andil dan } \\
\text { mengecam apa yang dilakukan } \\
\text { Israel dalam hal ini yang } \\
\text { menutup kompleks Masjid Al- } \\
\text { Aqsa atau lebih tepatnya } \\
\text { meningkatkan penjagaan di } \\
\text { kompleks Al-Aqsa yang masih } \\
\text { dalam status quo tersebut }\end{array}$ \\
\hline Appeals to Principles & $\begin{array}{lrr}\text { Amerika Serikat } & \text { sangat } \\
\text { prihatin } & & \text { dengan } \\
\text { ketegangan yang } & \text { terjadi } \\
\text { disana } & & \end{array}$ & $\begin{array}{l}\text { Umat Muslim tidak bisa } \\
\text { beribadah dengan bebas } \\
\text { sebagaimana haknya dan inilah } \\
\text { yang memicu konflik lagi } \\
\text { diantara Israel dan Palestina }\end{array}$ \\
\hline Consequences & $\begin{array}{l}\text { Yang terjadi adalah ada } \\
\text { alasannya yang membuat } \\
\text { Israel meningkatkan } \\
\text { keamanan di Situs Suci itu }\end{array}$ & $\begin{array}{l}\text { Indonesia peduli terhadap } \\
\text { Palestina, Indonesia yang } \\
\text { mayoritas umat muslim pasti } \\
\text { begitu prihatin dengan keadaan } \\
\text { yang terjadi disana }\end{array}$ \\
\hline
\end{tabular}

Sumber: Data Olahan Peneliti, 2018.

Dalam hal ini, media massa berperan cukup besar mengkontruksi berita. Framing media-media tersebut terlihat sesuai dengan kepentingan bahkan keberpihakan dari mediamedia tersebut dimana harusnya media yang ideal yang menjadi wadah untuk mendapatkan informasi menyajikan fakta informasi, akurasi data, pertanggung jawaban dari penulis berita serta etika media itu sendiri (Tamburaka, 2013, p. 247). Dari hasil penelitian dua berita dari kedua media pada periode tanggal yang sama. Kedua media ini berusaha untuk mengambarkan sudut pandang mereka masing - masing terhadap yang terjadi di A-Aqsa. Sesuai dengan yang dikatakan bahwa media bisa saja mengambil kesimpulan dan media mempunyai kesempatan untuk membuat segala sesuatu sesuai dengan pandangannya yang tidak mungkin benar - benar objektif serta tidak berkaitan dengan kepentingan politik dan ekonomi suatu Negara (Biagi, 2010). 
Tabel 4. Perbedaan Framing pada Artikel 2 Edisi 23 Juli 2017 Cnnindonesia.com dan Kompas.com

\begin{tabular}{|c|c|c|}
\hline Media Online & Cnnindonesia.com & Kompas.com \\
\hline Frame & $\begin{array}{l}\text { Keadaan di Al-Aqsa } \\
\text { semakin memburuk, PBB } \\
\text { Didesak segera bersidang }\end{array}$ & $\begin{array}{l}\text { Indonesia mengecam } \\
\text { penembakan di Al-Aqsa, PBB } \\
\text { diminta bertindak }\end{array}$ \\
\hline Metaphors & $\begin{array}{l}\text { cnnindonesia.com } \\
\text { menuliskan kata kemelut. } \\
\text { Menambahkan kata } \\
\text { kemelut pada judul } \\
\text { menurut peneliti adalah } \\
\text { bagaimana } \\
\text { cnnindonesia.com ingin } \\
\text { mengagambar bahwa di } \\
\text { Yerusalem terjadi bahaya }\end{array}$ & $\begin{array}{l}\text { Kompas.com menuliskan } \\
\text { Diminta dijudul, seperti } \\
\text { perumpamaan bahwa PBB } \\
\text { diminta atau diinginakan untuk } \\
\text { menindaklanjuti apa yang terjadi } \\
\text { di Al-Aqsa }\end{array}$ \\
\hline Catchphrases & $\begin{array}{l}\text { Penulisan kata "didesak" } \\
\text { pada judul serta beberapa } \\
\text { kata mendesak yang } \\
\text { menekankan bahwa kasus } \\
\text { di al-Aqsa harus cepat } \\
\text { diselesaikan oleh PBB dan } \\
\text { didukung beberapa Negara } \\
\text { yang juga mendesak } \\
\text { termasuk Indonesia }\end{array}$ & $\begin{array}{l}\text { Penulisan kata } \text { PBB pada judul } \\
\text { agar terlihat bahwa PBB } \\
\text { berpengaruh } \text { serta ingin } \\
\text { minindaklanjuti apa yang terjdi } \\
\text { di Al-Aqsa }\end{array}$ \\
\hline Exemplaar & $\begin{array}{l}\text { Dengan mengutip kata } \\
\text { Presiden Indonesia Jokowi } \\
\text { di Yogyakarta } \\
\text { cnnindonesia.com yang } \\
\text { ingin menegaskan bahwa } \\
\text { beberapa Negara memang } \\
\text { mendesak PBB untuk } \\
\text { bersidang }\end{array}$ & $\begin{array}{l}\text { Dengan mengutip wawancara } \\
\text { meutya Hafid } \\
\text { mempertegas bingkai yang } \\
\text { dibuat yang menurut peneliti } \\
\text { membuat citra Indonesia baik } \\
\text { dan peduli terhadap Al-Aqsa } \\
\text { dengan diwawancaranya salah } \\
\text { satu orang penting di } \\
\text { pemerintahan Indonesia. } \\
\text { Memang benar pemerintah } \\
\text { Indonesia mendukung Palestina } \\
\text { serta meminta PBB agar segera } \\
\text { bertindak }\end{array}$ \\
\hline Depiction & $\begin{array}{l}\text { Perseteruan yang semakin } \\
\text { memburuk antar kedua } \\
\text { Negara yaitu Israel dan } \\
\text { Palestina, Israel yang tetap } \\
\text { baik memberikan akses } \\
\text { akan tetapi pihak Palestina } \\
\text { menyatakan menutup } \\
\text { semua kontak resmi } \\
\text { kepada Israel yang } \\
\text { menyebabkan semakin } \\
\text { memburuknya hubungan }\end{array}$ & $\begin{array}{l}\text { Indonesia mengecam yang } \\
\text { dilakukan Israel terhadap } \\
\text { penembakan tiga Jemaah } \\
\text { Palestina di kawasan kompleks } \\
\text { Masjid Al-Aqsa dan mendukung } \\
\text { agar PBB segera bertindak untuk } \\
\text { menghetikan kekisruhan yang } \\
\text { ada disana sebab kekisruhan } \\
\text { disana tidak beralasan dan } \\
\text { mengecam karena telah } \\
\text { memperketat keamanan untuk }\end{array}$ \\
\hline
\end{tabular}




\begin{tabular}{|c|c|c|}
\hline & antar dua Negara & beribadah umat Muslim \\
\hline Visual Images & $\begin{array}{l}\text { Gambar disini } \\
\text { memperlihatkan kericuhan } \\
\text { yang ada diluar Masjid Al- } \\
\text { Aqsa yang warga } \\
\text { sepertinya berlarian } \\
\text { karena adanya api atau } \\
\text { tembakan yang menyerang } \\
\text { mereka }\end{array}$ & $\begin{array}{l}\text { Gambar Masjid Al-Aqsa dari } \\
\text { kejauhan yang mempertegas } \\
\text { judul berita yaitu menyembutkan } \\
\text { lokasi Al-Aqsa untuk memberi } \\
\text { keterangan seperti apa bentuk } \\
\text { Masjid Al-Aqsa serta sekitarnya } \\
\text { yang menegaskan bahwa berita } \\
\text { ini mengenai Al-Aqsa }\end{array}$ \\
\hline Roots & 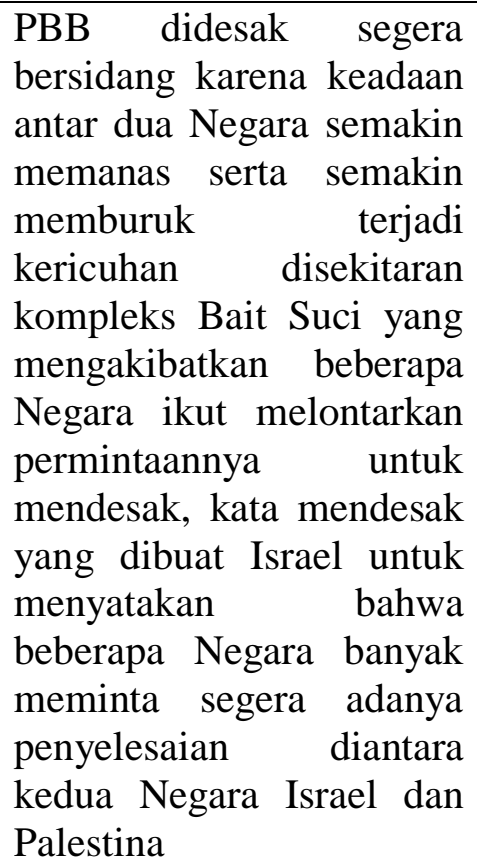 & $\begin{array}{l}\text { Kekerasan yang harus dihentikan } \\
\text { di Israel karena dinilai } \\
\text { melanggar HAM serta pihak } \\
\text { Indonesia yang mengecam keras } \\
\text { terjadinya penembakan tiga } \\
\text { Jemaah dikawasan itu pada saat } \\
\text { terjadi bentrokan antara warga } \\
\text { Palestina dan pasukan keamanan } \\
\text { Israel }\end{array}$ \\
\hline Appeals to Principles & $\begin{array}{l}\text { Isarel } \\
\text { mempersilahkan masjid } \\
\text { al-Aqsa untuk pria yang } \\
\text { berusia } 50 \text { tahun keatas } \\
\text { dan perempuan semua } \\
\text { umur }\end{array}$ & $\begin{array}{lll}\text { RI peduli terhadap apa yang } \\
\text { terjadi di Al-Aqsa } & \text { yang } \\
\text { disinyalir melanggar HAM } & \end{array}$ \\
\hline Consequences & $\begin{array}{l}\text { Detektor logam memang } \\
\text { membuat kekerasan } \\
\text { meningkat dan ada } \\
\text { beberapa penyerangan dari } \\
\text { Israel tetapi terlihat selalu } \\
\text { dimulai oleh Palestina }\end{array}$ & $\begin{array}{l}\text { Membuat masyarakat Indonesia } \\
\text { peduli dengan apa yang terjadi di } \\
\text { Al-Aqsa serta menentang } \\
\text { pemasangan detector logam } \\
\text { yang membuat pembatasan umat } \\
\text { Muslim untuk beribadah serta } \\
\text { menimbulkan konflik lagi untuk } \\
\text { Palestina dan Israel.Palestina } \\
\text { mendapat dukungan dari } \\
\text { Indonesia }\end{array}$ \\
\hline
\end{tabular}

Sumber: Data Olahan Peneliti, 2018.

Terkait dengan perbedaan pemberitaan tragedi kemanusiaan di alAqsa ini, McQuail mengatakan bahwa media massa berperan besar dalam kehidupan ekonomi dan politik (McQuail, 2011, pp. 105-254). Ekonomi politik Internasional dalam kaitannya dengan kedua 
media online cnnindonesia.com dan kompas.com mereka berbeda dalam memberitakan kasus tersebut. Karena setiap media yang pasti membawa posisi politik negara-negara mereka bernaung, dalam hal ini kompas.com yang tidak lain berasal dari Indonesia sedangkan cnnindonesia.com media barat yang bekerja sama dengan perusahaan besar media di Indonesia yang membuat kedua media ini tidak akan jauh jauh dari kebijakan luar negeri Negara asal karena kaitannya media dengan ekonomi politik Internasional. Kompas.com media nasional yang memiliki ideologi yang kuat yang intinya ingin menyajikan berita yang sesuai fakta serta menghargai perbedaan dan keragaman dan menjungjung tinggi nilai kemanusiaan (Inside.kompas, n.d) yang menegaskan bahwa media kompas.com sama dengan kebijakan luar negeri Indonesia yang dari awal mendukung solusi untuk kedua negara yaitu Israel dan Palestina serta yang secara kosisten menyampaikan komitmennya untuk membantu penyelesaian konflik yang berkepanjangan antara Palestina dan Israel (Kemlu, 2016) yang dalam hal ini kasus Al-Aqsa yang membuat Indonesia sangat khawatir dengan semakin memburuknya situasi di kompleks Masjid Al-Aqsa yang adanya tindak kekerasan oleh pihak keamanan Israel serta mendesak Israel menghentikan pembatasan beribadah (Kemlu, 2017).

Cnnindonesia.com yang berasal dari perusahaan CNN dari Atlanta Amerika Serikat yang dianggap liberal di Amerika sementara itu diluar negeri cnnindonesia.com memang sangat terkenal sebagai pro Amerika (Satujam, 2016). Terbukti dalam penelitian ini peneliti melihat karena adanya berita pada tanggal 20 Juli 2017 yang sangat tegas menuliskan bahwa Amerika Serikat prihatin atas apa yang terjadi di Al-Aqsa dimana cnnindonesia.com menulis judul beritanya dengan menyebutkan Gedung Putih 'prihatin' tanda kutip karena memang tidak bisa dipungkiri walaupun gedung putih mengungkapkan keprihatinanya akan tetap secara jelas bahwa Amerika Serikat masih tetap pro Israel terbukti pada tanggal 14 Mei 2018 di media online cnnindonesia.com yang menuliskan bahwa Amerika Serikat meresmikan pembukaan kedutaan besar Amerika Serikat di Yerusalem sebagai pengakuan Ibu Kota Israel yang resmi mengesahkan undang - undang kongres AS yang mengharuskan Amerika untuk memindahkan kedutaan dari Tel Aviv ke Yerusalem yang ditegaskan di situs resmi white house. Banyak sekali pembuktian Amerika Serikat yang menunjukan posisi politiknya dengan salah satunya menyatakan menarik diri dari UNESCO pada tanggal 31 Desember 2017 yaitu badan budaya dan pendidikan perserikatan Bangsa - Bangsa (PBB) (CNN Indonesia, 2017) yang telah lebih dulu menyatakan dukungan pada putusan yang pro Arab dan memutus hubungan Israel dengan wilayah suci Jerusalem dengan meyebutkan di teks berita bahwa resolusi UNESCO bahwa kompleks Masjid Al-Aqsa dengan nama Islam yaitu Al-Aqso dan Al- Haram Al Sharif (CNN Indonesia, 2016).

Setelah melakukan penelitian dapat disimpulkan bahwa cnnindonesia.com dan kompas.com selaku kedua media yang menjadi medium dalam informasi yang memiliki ideologi sendiri dalam penyampaian informasi inilah yang membuat peneliti melakukan penelitian ini dengan memakai tiga konsep ini dalam menuliskan berita - berita yang mereka tulis yaitu salah satunya mencerimankan politik, masyarakat dan budaya seperti yang dilakukan cnnindonesia.com yang ingin terlihat bahwa netral dalam menuliskan sebuah berita walaupun memang sangat jelas terlihat bahwa cnnindonesia.com lebih pro Israel yang 
dalam hal ini di dukung Amerika Serikat sebagai Negara asal dari media CNN itu sendiri sedangkan kompas.com yang selalu ingin menonjolkan peranan Indonesia dalam setiap beritanya, serta dengan jelas menuliskan dukungan kepada Palestina karena dalam hal ini Indonesia yang tidak lain Negara asal media online kompas.com adalah Negara asalnya yang hampir keseluruhan masyarakatnya muslim dan memang mendukung Palestina yang berkaitan dengan yang dikatakan oleh Denis McQuail yaitu dimana media secara umum harus beroperasi secara keseluruhan atau sebagian pasti mengikuti dikte ekonomi pasar bahkan untuk menarik perhatian pemerintah dengan menjadikan produk utama adalah khalayak (McQuail, 2011, pp. 105-106). Selama ini kompas.com menuliskan dengan tegas bahwa Indonesia mendukung Al-Aqsa yang menurut Denis McQuail dalam hal ini media juga bisa menjadikan media sebagai sarana oleh pemerintahannya untuk memasuki kepentingan politik.

Pada berita - berita yang diberitakan oleh kedua media mempresentasikan bahwa fenomena kemanusiaan di Al-Aqsa adalah masalah yang serius dan harus ditanggapi dan didukung oleh pihak Internasional dalam penyelesaian konfliknya yang dinilai kedua media melanggar HAM. Ditemukan adanya indikasi keberpihakan yang sama - sama membahas tentang adanya pelanggaran kemanusiaan di Al-Aqsa tetapi digambarkan bahwa awal terjadinya konflik disebabkan oleh salah satu Negara dan ada beberapa Negara yang digambarkan mendukung Palestina sedangkan kompas.com sangat terlihat ingin menonjolkan peran Indonesia dengan beberapa kali menegaskan dukungan Indonesia dan posisi Indonesia terhadap fenomena di Al-Aqsa.

Teori framing sendiri menurut Goffman adalah dimana pendekatan untuk melihat realitas itu yang dibentuk dan dikonstruksi oleh media yang bisa mengakibatkan berubahnya aspek oleh adanya sajian tertentu yang menonjol (Goffman, 1986, p. 51), ini terlihat bagaimana cnnindonesia.com menggambarkan bahwa Amerika peduli atas apa yang terjadi di Al-Aqsa dengan mengatakan bahwa Amerika prihatin atas apa yang terjadi. Kesimpulannya bahwa cnnindonesia.com lebih menggambarkan agama lain dibandingkan agama islam sehingga menimbulkan kontruksi bahwa apa yang dilakukan Israel dengan cara memperketat keamanan di kompleks Masjid Al-Aqsa yang banyak ditulis cnnindonesia.com degan sebutan bait suci. Terlihat juga bahwa disini cnnindonesia.com ingin mengangkat citra Israel agar terlihat tidak salah dalam mengambil keputusan memasang detektor logam. Sedangkan kompas.com yang media dalam negeri lebih kepada menonjolkan peran Indonesia terkait masalah ini dan kemungkinan karena penduduk Indonesia kebanyakan muslim kompas.com menuliskan tempatnya lebih sering dengan sebutan kompleks masjid Al-Aqsa dibanding Bukit Bait Suci yaitu sebutan untuk orang Yahudi untuk komplek AlAqsa.

Gamson mengatakan menurut Eriyanto dalam bukunya Analisis Framing bahwa wacana media menentukan bagaimana khalayak memahami suatu isu dan fenomena itu sendiri yang berarti apa yang ditulis (Eriyanto, 2002, p. 217) cnnindonesia.com dan kompas.com menentukan penelitian kita terhadap fenomena kemanusiaan di Al-Aqsa. Meskipun kasus Al-Aqsa sudah mencapai titik temu dengan di cabutnya detektor logam akan tetapi permasalahan antara kedua Negara yaitu Israel dan Palestina masih berlanjut 
hingga saat ini dan masyarakat Palestina masih menuntut hak - haknya terhadap Masjid AlAqsa.

Cnnindonesia.com yang lebih kepada mengikuti ideologi Negara asal yaitu Amerika Serikat yang menunjukan dimana Amerika Serikat yang mendukung jelas serta Trump pada saat kampanye sering mengaku dirinya "sahabat sejati" Israel dengan menuliskan berita yang berusaha netral sedangkan Kompas.com dari awal mendukung Palestina dalam kebijakan politiknya sesuai dengan situs kemenlu yang menuliskan posisi Indonesia terhadap Palestina (Kemlu, 2016), yaitu:

1. Mendukung solusi dua negara (Israel dan Palestina), berdasarkan hukum internasional dan HAM, dan agar kedua belah pihak mematuhi parameter yang telah dibentuk dalam sejumlah resolusi PBB.

2. Menekankan perlunya sikap berimbang (imparsial) dari masyarakat internasional dalam membantu penyelesaian masalah Palestina dan mendorong proses perdamaian.

3. Mendukung pentingnya menjaga keberlangsungan kerja UNRWA (United Nations Relief and Works Agency for Palestine Refugees in the Near East) untuk memberikan pelayanan kepada para pengungsi Palestina, serta ikut menyerukan perlunya keterlibatan masyarakat internasional dalam membantu para pengungsi Palestina, terutama dalam menjamin masa depan anak-anak.

4. Indonesia secara konsisten menyampaikan komitmennya untuk membantu penyelesaian konflik yang berkepanjangan antara Palestina dan Israel.

Pernyataan diatas bisa disimpulkan mengapa kompas.com lebih menuliskan dukungan Indonesia terhadap Palestina karena Indonesia adalah negara yang selalu kosisten dengan komitmennya untuk membantu menyelesaikan konflik berkepanjangan antara Palestina dan Israel. Dengan demikian apapun yang ditulis media tidak bisa dipisahkan dari kehidupan ekonomi serta politik suatu negara disini kaitannya dengan kasus Al-Aqsa yang di analisis dikaitakan dengan Amerika Serikat dan Indonesia yang bahkan sudah terlihat dari kebijakan luar negera masing - masing negara yang menggambarkan keberpihakan negara negara masing - masing yang tidak menutup kemungkinan cnnindonesia.com dan kompas.com lakukan adalah mengikuti kepentingan ekonomi dan politik mereka.

\section{PENUTUP}

Berita terkait fenomena kemanusiaan di Al-Aqsa pada periode 20 - 23 Juli 2017 pada dua media online Cnnindonesia.com dan Kompas.com, memiliki kaitan dengan media massa dan ekonomi politik internasional. Permasalahan mengenai fenomena kemanusiaan di AlAqsa menjadi masalah internasional yang mana banyak media massa yang memberitakannya tidak terkecuali kedua media online yaitu cnnindonesia.com dan kompas.com. Sehingga kedua media ini memiliki peran pembaca media online dalam menangkap informasi berdasarkan pandangan dari kedua media online ini serta mempunyai perbedaan dalam menangkap dan memberitakan kasus tersebut. Hal ini telihat dari hasil analisis menggunakan analisis framing William A. Gamson dan Andre Modigliani bahwa kedua media dari dua berita hanya satu menggambarkan atau fokus yang sama dengan sama - sama menuliskan peran Indonesia dalam mendukung Palestina. Terlihat dari hasi penelitian permasalahan AlAqsa yang berkaitan dengan media massa dan media dan ekonomi politik internasional tidak 
dapat dipisahkan dari kasus ini karena memang dari kepemilikan yang berbeda serta asal dari media tersebut yang berbeda tidak menutup kemungkinan bahwa adanya keberpihakan cnnindonesia.com dan kompas.com dengan Negara asal media tersebut.

Penelitian ini dapat dilanjutkan untuk diskusikan dikelas dan dikembangkan lebih mendalam dalam mengkaji media massa. Berita terkait fenomena kemanusiaan di Al-Aqsa harusnya diberitakan secara objektif dan berimbang agar masyarakat tidak bingung. Keberpihakan media tertentu terhadap pemilik modal seharusnya dikesampingkan dan tidak mempengaruhi isi berita pada sebuah media. Penelitian ini membantu masyarakat yang setiap hari berhadapan dengan media online untuk mendapatkan informasi agar lebih jeli untuk memilih media masa yang lebih kritis dalam memaknai pesan karena sangat berperan besar dalam membuntuk perspektif serta opini masyarakat.

\section{REFERENSI}

Buku penulis tunggal

Biagi, S. (2010). Media/Impact: An Introduction to Mass Media (9th Edition ed.).

(I. Mochammad, \& W. M. Wulung, Trans.) Jakarta: Penerbit Salemba Humanika.

Tamburuka, A. (2013). Literasi Media: Cerdas Bermedia Khalayak Media Massa. Jakarta: Rajawali pers.

Goffman, E. (1986). Frame analysis an essay on the organization of experience. Northeastern university press.

McQuail. (2010). McQuali's mass communication theory (6th Edisi ed.). London: Sage Publications.

McQuail. (2011). Teori komunikasi massa mcquail (6 ed.). (P. I. Izzati, Trans.) Jakarta: Penerbit salemba humanika.

Vivian, J. (2008). Teori Komunikasi Massa, (8th Edition ed.). (T. W. B.S, Trans.) Jakarta: Pearson Education.

Figenschou, T. U. (2014). Al Jazeera and the Global Media Landscape The South Is Talking Back. New York: Routledge.

Eriyanto. (2002). Analisis framing konstruksi, ideologi, dan politik media. Yogyakarta: Lkis.

Bakry, U. S. (2016). Metode Penelitian Hubungan Internasional. Yogyakarta: Pustaka Pelajar.

Pambayun, E. L. (2013). One stop qualitative of research methodology in communication. Jakarta: Lentera Ilmu Cendekia.

Tamburaka, A. (2013). Literasi Media:Cerdas Bermedia Khalayak Media Massa. Jakarta: Rajawali Pers.

Online Media:

liputan6. (2014, March 1). Retrieved October 18, 2017, from bisnis.liputan6.com: http://bisnis.liputan6.com/read/2017025/chairul-tanjungkibarkan-cnn-indonesia

Kompas. (n.d). Retrieved October 5, 2017, from inside.kompas.com: http://inside.kompas.com

Inside.kompas. (n.d). Retrieved Februari 2, 2018, from inside.kompas.com: https://inside.kompas.com/about-us

Kompas. (2017, July 23). Penembakan di Al-Aqsa Dinilai Langgar HAM, 
PBB Diminta Bertindak. Retrieved September 20, 2017, from nasional.kompas.com: http://nasional.kompas.com/read/2017/07/23/13491021/penembakan-di-al-aqsadinilai-langgar-ham-pbb-diminta-bertindak

CNN Indonesia. (2017, July 23). PBB Didesak Segera Bersidang Atasi Kemelut

di Yerusalem. Retrieved September 20, 2017,

from cnnindonesia.com:

https://www.cnnindonesia.com/internasional/20170723022610-120-229700/pbbdidesak-segera-bersidang-atasi-kemelut-di-yerusalem/

Ferandy, M. (2016, Juni 22). Satujam. Retrieved Maret 2018, 1, from

Satujam.com: https://satujam.com/sejarah-cnn/

CNN Indonesia. (2017, Januari 21). Retrieved Juli 4, 2018,

from www.cnnindonesia.com:

https://www.cnnindonesia.com/internasional/20170121121110-134-187894/merabaarah-kebijakan-amerika-dalam-komando-presiden-trump

CNN Indonesia. (2017, Oktober 13). Retrieved Juli 4, 2018,

from www.cnnindonesia.com:

https://www.cnnindonesia.com/internasional/20171013030421-134-248098/as-

nyatakan-keluar-dari-unesco

CNN Indonesia. (2016, Oktober 19). Retrieved Juli 4, 2018,

from www.cnnindonesia.com:

https://www.cnnindonesia.com/internasional/20161019014718-120-166414/unesco-

keluarkan-resolusi-al-aqsa-milik-palestina

Official Document:

Kemlu. (2016, Januari 20). Retrieved Juli 4, 2018,

from www.kemlu.go.id: https://www.kemlu.go.id/id/kebijakan/isu-khusus/Pages/IsuPalestina.aspx

Kemlu. (2017, Juli 23). Retrieved Juli 4, 2018, from www.kemlu.go.id: https://www.kemlu.go.id/id/berita/Pages/Menlu-RI-BahasSituasi-di-Kompleks-Masjid-Al-Aqsa-dengan-Menlu-AS.aspx

Whitehouse. (2017, Desember 7). Retrieved Agustus 6, 2018, from www.whitehouse.gov: https://www.whitehouse.gov/briefingsstatements/support-president-trumps-decision-recognize-jerusalem-israels-capital/ 